\title{
Who Cares about Care Work in Japan?
}

Kea Wāku: Sasaeru Chikara o Dō Hagukumu ka (Care Work: How do we Foster the Strength to Care?), by Nishikawa Makiko. Tokyo: Nikkei Shinbun Shuppansha, 2008, 248 pp., 2000 yen (ISBN 978-4-532-31430-9).

Kea suru Koto (Performing Care) Volume 2 of Kea Sono Shisō to Jissen - (Care: Ideology and Practice), edited by Ueno Chizuko, Okuma Yukiko, Osawa Mari, Jinno Naohiko, and SoedaYoshiya. Tokyo: Iwanami Shoten, 2008. 266 pp., 2200 yen (ISBN 978-4-00-028122-5).

Kea o Jissen suru Shikake (Volume 6 of Kea Sono Shisō to Jissen - (Care: The Ideology and Practice), edited by Ueno Chizuko, Okuma Yukiko, Osawa Mari, Jinno Naohiko, and SoedaYoshiya. Tokyo: Iwanami Shoten, 2008. 294 pp., 2400 yen (ISBN 978-4-00-028126-3).

The context behind the books under review is the rapidly ageing population, declining birthrate, greater numbers of women seeking paid work, the fact that women are predominantly the main caregivers of children and the aged, and public spending on social welfare not keeping pace with the increase in the portion of the population who are elderly or infirm. Nishikawa's book examines care work both as it is configured privately within the family, in particular focusing on childcare, and publicly when care of the elderly is outsourced to paid employees. The 6 volume Kea Sono Shisō to Jissen draws on the expertise of a diverse range of academics and practitioners involved in various aspects of the care industry. The series covers a breadth of issues related to care work including discussions of what care actually means, the work of caregivers, the effects of caring for family members on the caregivers, the policy framework of care and the different ways in which care can be conducted. Given my research interest in care workers, particularly care work with the aged, 
my discussion of these works focuses specifically on a discussion of workers in the care industry.

Nishikawa sets herself the task of questioning two myths which exist about both unpaid care work, focusing on the care of children, and paid care work concentrating on the elder care sector. The first myth she tackles is the myth that any woman can perform care work, and the second is that care work is an unskilled or non-specialist form of work. Based on fieldwork and referring to numerous surveys conducted on care work, Nishikawa poses the question: what is the most desirable form of care work that can be created? To respond she divides her book into 2 sections, with the first analysing informal care and the second focusing on formal care.

In examining informal care work Nishikawa presents the benefits of overcoming the stereotype of 'women as the main caregivers' to suggest how paid care work can be improved. Nishikawa argues that both men and women need to participate in informal care in the home. For Nishikawa, shared caring in the home not only creates a better work-life balance but, she argues, will also lead to care work being more highly valued by society generally. Using a range of data Nishikawa concludes that households where women are employed as regular workers, rather than as non-regular workers, are better off in terms of accruing social capital and are better able to adapt to care work. In other words, these households to some extent have challenged sexist stereotypes restricting women to the role of main care giver and have had an impact on male workers' work lives. I concur with Nishikawa's position that men and women can both perform care work and that it is important to encourage women and men to perform care work which will contribute to improving everyone's work-life balance. It is quite possible, as Nishikawa asserts, that once women and 
men share care work more equitably, then care work will be valued more highly in wider society-how this will happen and how long this will take, however, is another question. Decreasing working hours, mandating the introduction of childcare leave policies in all workplaces, changing organisational cultures to support those who take leave, removing financial and career disadvantages for those who take leave as well as insisting that men take childcare leave are a welcome beginning, and may well bring about the social change needed to increase opportunities for widespread informal care. One difficulty however, is that recent employment trends don't support the likelihood of more women, or for that matter men, now or in future generations gaining or continuing in secure employment as regular workers. This diminishes both their access to leave and their ability to financially support themselves if a stronger social welfare system is not developed.

The context for the discussion of paid care work is the premise that social changes, such as women and men sharing care work in the home, need to occur, but declining rates of marriage and numbers of children being born, as well as an increasing divorce rate, mean that there will be too few households able to provide for all of Japan's care needs. Nishikawa argues that the increasing influence of informal care work, because more women and men are sharing care work, will improve the overall quality of all care work, which will lead to meaningful and cooperative partnerships with specialised care services and providers. For Nishikawa the focus is on specialist organisations and how training and skills for care workers can be improved. Nishikawa argues that increasing the skill set of care workers, specifically on-the-job training and qualifications, will lead to better wages and conditions.

In support of Nishikawa's argument that on-the-job training for elder care workers is a more effective method of training, I draw on my own fieldwork with home help workers. The home 
help workers I interviewed from March-June 2009 gained their skills as home help workers through previous experiences such as caring for a family, or 'on-the-job' by working alongside an experienced home helper. They possessed a depth and variety of skills rarely recognised in the public sphere, including the ability to relate and interact with a range of clients with differing needs, to satisfy their clients' needs, and to prepare meals for their clients which appeal to their taste, often with limited ingredients. If a home help worker is responsible for bathing their clients, then they need to be able to physically lift their client and manipulate limbs without causing pain, injury or discomfort. All the home helpers I interviewed possessed at least the minimum entry level home help certificate and a number also possessed a diploma in elder welfare work. Of more importance however, since recent reforms of the Long Term Care Insurance Law, is the ability to perform the tasks they are contracted to perform in a limited amount of time. The majority of home helpers I interviewed were employed as non-regular workers - effectively on a 'just in time' basis, where they were contracted to perform tasks in blocks of 30 minutes to one hour. The trend towards the Taylorisation of care work and the reduction in contact time between home helper and client requires further research. A small number of home help workers were employed as regular employees, yet even their wages and conditions were on average lower than those in other industries. As one home helper commented, 'working in a supermarket is better [than home help work] because even though it's the same low pay and poor conditions you are guaranteed regular hours and shifts' (Broadbent interview 2009).

Does improving the skills and qualifications of elder care workers necessarily lead to better pay and conditions, as Nishikawa asserts? In many cases it means workers are required to take on more tasks with little or no increase in pay and conditions. While the sexism surrounding the value of women's work and the value of care work persists, wages and conditions will 
continue to remain low and the assumption that an increase in skills will improve wages and conditions doesn't challenge the persistence of sexism. Wages and conditions are only improved when workers challenge management and systems are developed to determine wages and conditions. Many of the benefits enjoyed by Japanese workers were largely achieved only when workers fought management. The role of unions is one of the silences in Nishikawa's book, and is only mentioned briefly in one of the chapters in Volume Two of the Kea series. Granted, unions represent only 18 percent of the total Japanese workforce and rarely rate a mention in terms of their significance in Japanese society, but there are unions which organise both care workers employed in elder facilities and home help workers. The number of workers unionised in the elder care sector compared to those employed in that sector is tiny; however, to overlook the role of unions as the defenders of working class conditions is problematic. Given the relative quiescence of Japan's union movement, and in particular the reluctance of the majority of Japan's unions to address issues facing women or non-regular workers (the majority of whom are women), women have needed to rely on courts to achieve redress in terms of discrimination in wages and employment conditions. In this respect academics have fulfilled an important role in researching issues of equal pay and comparative worth through detailed studies of industries employing large numbers of women. Professor Mori Masumi is overseeing a range of studies at present. It is studies such as these which contribute significantly to detailing the skills needed but not included in calculations of the pay and remuneration of many feminised occupations.

Like Nishikawa's book, the series Kea sono Shisō to Jissen covers elder and disability care work, including the philosophies of care, from the perspectives of caregivers, individuals, families, care workers, the policy framework and care organisations. The 6 volumes, comprising 75 chapters, canvass the diversity of workplaces and facilities including 
community, public, and private organisations, the diversity of staff from volunteers to paid staff and regular and non-regular workers, and changes in the public policy arena associated with the reforms in the care sector. The coverage of the series is welcome given the growing demand for care and the significance of the care industry, and it is conceivable future volumes will document developments in this significant sector. This review can't possibly begin to do justice to the research, expertise and data contained in the series, so in order to discuss some of the volumes I have selected two chapters from two of the volumes which examine work and factors which impact those employed in the elder care sector. I have selected these chapters to continue to develop themes raised in Nishikawa's book. I review Hotta Satoko's 'Kaigo Rōdō Shijō to Kaigo Hoken Jigyō ni Juji suru Kaigo Shoku no Jittai' in volume 2, Kea suru Koto, and Eiwa Yoshinosuke's 'Kaigo Shisetsu no Fukushi Keieiron' in volume 6, Kea o Jissen suru Shikake.

Hotta's chapter is divided into two sections: the first provides an overview of employment in the care sector, arguing that to provide high quality, stable care it is essential to provide adequate training which will also act to retain care workers (p. 76), and the second focuses on the recommendations of a research group established to determine the conditions of care service organisations. Her discussion demonstrates the impact of the continuing explosion in demand for care services on creating demand for care employees and the dilemma created by insufficient numbers of care workers. By drawing on data of both home help caregivers and care workers employed in facilities we learn that the care sector is highly feminised with low pay and poor conditions, and employee turnover is very high with an annual average of over 30 percent. More than 80 percent of home helpers are non-regular workers, are on average in their mid 40s and are married. Those employed in facilities are younger and employed as regular workers (pp. 81-82). Hotta notes that many care workers possess entry level 
qualifications but is concerned with the low numbers of care workers possessing the elder care worker certification (Kaigo Fukushi Shi) - only 35\% of those employed in facilities and only $16 \%$ of home helpers (p. 82). Yet, as Hotta notes, the majority of care workers are committed to their work. To illustrate her point Hotta draws on data from a range of sources which indicate that the majority $(64.6 \%)$ of care workers employed in facilities chose the care sector (p. 84) and that the job provides them with satisfaction (64\%) (p. 86). The main concerns for care workers employed in facilities however, is whether they can provide adequate care for their patients $(56.9 \%)$ and that their wages are too low compared with the work they perform (50\%). For home help workers, the main concerns are being asked to perform tasks outside the specified range of tasks for that client (48.7\%) and lack of confidence as to whether they provide adequate care (41.8\%) (p. 87). Finally, the main reason care workers employed in facilities gave for quitting is dissatisfaction with pay and conditions (over 30\%). For home help workers family circumstances ranked high as the motivation for quitting, with pay and conditions ranking third (p. 88). Hotta's overview sets the scene for presenting a discussion of the Ministry of Welfare and Labour's recommendations for retaining welfare staff, as well as the Research Group to Determine the Conditions of Care Organisations. In summary, the Ministry's recommendations emphasise the need to improve and develop the working environment, provide career paths, and improve qualifications to retain high quality staff. In examining how to provide high quality and consistent care it is necessary to provide training to recruit and retain a stable workforce. The Research Group, during its three meetings in the (northern) autumn of 2007, interviewed nine organisations, including Rengō (the Japan Trade Union Confederation) and the Kaigo Fukushi-shi Kyōkai (the Age Care Professionals Association). It focused on how care services are delivered, career paths, wage levels and how staff is distributed. Ultimately, Hotta concludes, in order to recruit and retain a stable workforce it is essential that working conditions be addressed, but 
she also argues it is necessary to create workplaces which act to motivate people in order to retain them. What is meant by this however, is unclear.

Eiwa's chapter, 'Kaigo Shisetsu no Fukushi Keieiron' in Volume 6 of the series, Kea o Jissen suru Shikake, complements the themes discussed in Hotta's chapter as Eiwa discusses the changes in elder care facilities since the introduction of the Long Term Care Insurance law in 2000. At the time the chapter was written (September 2006) there were 5,759 elder care facilities nationally with a total of 392,000 residents (p. 134). As discussed earlier, to fit with the themes of employees and work, I will discuss this aspect of Eiwa's chapter. Eiwa notes the increased casualisation of the workforce since the introduction of the Law, which differs from pre-2000 when 80 percent of the workforce had to be employed on a regular basis. In comparison, since the year 2000 employers are able to hire several non-regular workers or casuals to represent one regular worker. In this way Eiwa argues employers are able to maintain a 1:3 ratio of staff to residents (p. 135). A further difference is seen in restrictions on how income is expended. When elder care facilities were funded by taxes from the national and local governments, the allocated funds were for wages and residents' living expenses. Under these funding guidelines it was forbidden to reduce workers' incomes as a way of cutting costs. Since the passing of the Law Eiwa argues elder care facilities' income is now seen as 'service compensation' and so the facility can expend income without restrictions (p. 136). In examining how the management of elder care facilities have changed, Eiwa concentrates on a study of Ehime prefecture where he notes in the year 2000, the first year after the Law was introduced, that the profit of elder care centres was high. In 2004 more than 40 percent of elder care facilities had recorded high profit levels - over 15 percent (p. 138). To illustrate further, he compares the profitability of two elder care facilities in 1999 (pre-Law) and 2004 (post-Law) periods. His comparison notes that one facility increased its profitability 
by reducing its wages and cutting expenditure on residents. Specifically it combined an increase in the number of non-regular workers, namely part-time workers, with a reduction in the wages of regular workers (p. 142). Expenditure on residents was also reduced in the areas of food, hygiene products and entertainment (p. 143). In the highly profitable facility, Eiwa notes that the proportion of non-regular workers was high prior to the Law and continued to increase with the introduction of the Law, and as a consequence of increased casualisation, work intensification has become normalised (p. 150). What is different since the introduction of the Law is that now regular workers are also literally 'paying the price'. In 2004 they received 50 percent less in wages than they did in 1999 (p. 142). Much of the cost of living in elder care facilities in the pre-Law period was covered by funding received from the government, but since the Law was introduced this has shifted to 'user pays' (p. 145). The impact of so much cost cutting is that many facilities are reducing expenditure on residents through cutting entertainment or charging for previously free services, such as for escorting residents on shopping trips. In facilities that provide services 'at a cost', residents on low incomes who have limited ability to pay thus don't receive any entertainment, and simply become institutionalised, as they can't afford the associated extra costs. Eiwa argues that as facilities become profit-focused they are reduced to facilities which care for the body only (p. 151). He argues that this will have a negative impact on employees or prospective employees who are motivated to work in the industry by a concern for or with providing a 'human' existence for the aged, which Hotta's research argues is the case for the majority of elder care workers. In this way, Eiwa argues that it is understandable why people leave the industry (p. 151).

When the Long Term Care Insurance Law was introduced in 2000 it was hailed as revolutionary, and a panacea to assure care for Japan's rapidly ageing population. Nearly a 
decade since the Law's introduction we are seeing problems emerging from the privatisation of a sector which provides an essential public good, particularly in a society where the social welfare net is almost non-existent. Nishikawa's book and the care series, especially the chapters reviewed here, indicate the necessity of improving wages and conditions in a sector that is desperate to recruit, train and retain significant numbers of staff to continue providing consistent care and a viable service. While we know that the previous Liberal Democratic Party (LDP) governments haven't funded the sector at a rate which kept pace with the growing demand, we also know that unless the elder care sector receives a major injection of funds, its ability to function will be severely limited. The decisions and tasks ahead of Prime Minister Hatoyama and his Democratic Party of Japan (DPJ) are formidable. 